\title{
Caracterização dos parâmetros físicos e químicos de composto de resíduos orgânicos produzido por meio de vermicompostagem
}

O objetivo desta pesquisa foi realizar a caracterização dos parâmetros físicos e químicos de composto de vermicompostagem oriundo de resíduo orgânico não cozido coletado no Restaurante Universitário da Universidade Federal do Tocantins, campus Palmas. O experimento foi realizado utilizando resíduos coletados entre março e julho de 2020 e seguindo a metodologia proposta por Lourenço e Coelho (2012). Foram adotados os métodos analíticos oficiais para fertilizantes e corretivos propostos pelo Ministério da Agricultura, Pecuária e Abastecimento (BRASIL, 2017) e os valores dos nutrientes foram comparados aos exigidos pela na Instrução Normativa $n^{\circ} 61$ de 8 de julho de 2020. Ao final do processo foram contadas 140 minhocas e obtido um substrato com condições de pH e umidade adequados para o uso na agricultura, mas com baixo teor de nitrogênio, alto teor de carbono orgânico e condições nutricionais abaixo das exigências mínimas determinadas pela Instrução Normativa, para alguns parâmetros.

Palavras-chave: Resíduos sólidos; Compostagem; Reciclagem.

\section{Characterization of physical and chemical parameters of organic waste compost produced by vermicomposting}

The objective of this research was to characterize the physical and chemical parameters of vermicomposting compost from uncooked organic waste collected at the University Restaurant of the Federal University of Tocantins, campus Palmas. The experiment was carried out using waste collected between March and July 2020 and following the methodology proposed by Lourenço and Coelho (2012). The official analytical methods for fertilizers and corrective measures proposed by the Ministry of Agriculture, Livestock and Supply (BRASIL, 2017) were adopted and the nutrient values were compared to those required by Normative Instruction No. 61 of July 8, 2020. At the end of in the process, 140 earthworms were counted, and a substrate was obtained with conditions of pH and humidity suitable for use in agriculture, but with low nitrogen content, high organic carbon content and nutritional conditions below the minimum requirements determined by the Normative Instruction, for some parameters.

Keywords: Solid waste; Composting; Recycling.

Topic: Engenharia Ambiental

Reviewed anonymously in the process of blind peer.

Keullen Lopes da Silva

Universidade Federal do Tocantins, Brasil

http://lattes.cnpq.br/9619816663476145 keullenlopes@gmail.com

Aurélio Pessôa Picanço (iD

Universidade Federal do Tocantins, Brasil

http://lattes.cnpq.br/5376510759690094

http://orcid.org/0000-0001-5277-1403

aureliopicanco@uft.edu.br

Thiago Costa Gonçalves Portelinha

Universidade Federal do Tocantins, Brasil

http://lattes.cnpq.br/1129700911428931

http://orcid.org/0000-0003-2489-9113

thiagoportelinha@mail.uft.edu.br
Received: 16/04/2021

Approved: 17/05/2021

\author{
Flávia Lucila Tonani \\ Universidade Federal do Tocantins, Brasil \\ http://lattes.cnpq.br/2543140405487892 \\ http://orcid.org/0000-0001-6598-5582 \\ flaviatonani@uft.edu.br
}

Referencing this:

SILVA, K. L.; PICANÇO, A. P.; PORTELINHA, T. C. G.; TONANI, F. L.. Caracterização dos parâmetros físicos e químicos de composto de resíduos orgânicos produzido por meio de vermicompostagem. Revista Ibero Americana de Ciências Ambientais, v.12, n.5, p.424434, 2021. DOI: http://doi.org/10.6008/CBPC21796858.2021.005.0034 


\section{INTRODUÇÃO}

A urbanização, fenômeno que tem ocorrido de forma acelerada e desordenada em diversas cidades brasileiras impacta direta e abruptamente o meio ambiente. As implicações das interferências antrópicas no meio são geralmente indesejadas dentro do cotidiano das cidades como, por exemplo, a geração acentuada de resíduos sólidos urbanos (RSU) (BUENO, 2019). No Brasil, a questão dos resíduos gerados em ambientes urbanos tem tomado proporções preocupantes, principalmente devido à presença mínima de soluções adequadas e sustentáveis para lidar com esses RSU. De acordo com a Associação Brasileira de Empresas de Limpeza Pública e Resíduos Especiais (ABRELPE), a população brasileira apresentou um crescimento de $0,75 \%$ entre 2016 e 2017, enquanto a geração per capita de RSU, um aumento de 0,48\%. A geração total de resíduos aumentou $1 \%$ no mesmo período, atingindo um total de 214.868 toneladas diárias de RSU no país (BUENO, 2019).

Todavia, o cenário no tocante ao gerenciamento dos RSU também pode ser encarado por outro prisma. O Brasil tem elevado potencial de aplicação de técnicas de tratamento dos RSU, devido à grande geração de resíduos orgânicos. No âmbito dos resíduos sólidos domiciliares, por exemplo, geralmente a parcela de lixo orgânico chega a representar mais da metade do total coletado no país, de acordo com a Associação Brasileira de Empresas de Limpeza Pública e Resíduos Especiais (ABRELPE, 2013). Assim o estudo de medidas menos impactantes para o gerenciamento dos resíduos sólidos é uma alternativa para os problemas enfrentados nas cidades. De fato, é importante que os RSU sejam devidamente afastados do ambiente urbano, contudo é preciso que a estrutura do sistema seja repensada para que novos resultados sejam possíveis. As cidades devem possuir sistemas de tratamento de RSU a fim de diminuir o volume de resíduos que precisa ser depositado nos aterros sanitários.

A vermicompostagem tem potencial para ser uma dessa alternativas sustentáveis, técnica simples e bastante eficiente de reciclar matéria orgânica vegetal e animal. Nessa perspectiva esse estudo tem por objetivo caracterizar os parâmetros físicos e químicos de composto de vermicompostagem oriundo de resíduo orgânico não cozido coletado no Restaurante Universitário da Universidade Federal do Tocantins, campus Palmas.

\section{REVISÃO TEÓRICA}

\section{Dados sobre resíduos reciclados no Brasil}

De acordo com o Diagnóstico de Resíduos Sólidos do Sistema Nacional de Informações sobre Saneamento (SNIS), o Brasil coletou em 2019 em média 0,99 kg/hab./dia de resíduos domiciliares e públicos. Estima-se que foram coletadas cerca de 65,11 milhões de toneladas por ano ou 178,4 mil toneladas por dia de resíduos sólidos urbanos nos municípios brasileiros (BRASIL, 2019).

Do total coletado a massa de resíduos recicláveis foi de apenas $13,5 \mathrm{~kg} / \mathrm{hab}$./ano, equivalente a 1,6 milhão de toneladas em 2019, ou seja, para cada $10 \mathrm{~kg}$ de resíduos disponibilizado para a coleta, apenas 374 gramas foram coletadas de forma seletiva. No que diz respeito à destinação das 65,11 milhões de toneladas de resíduos coletados em 2019, o diagnóstico aponta a recuperação de 305 mil toneladas, 
recebidas em 73 unidades de compostagem, o que representa menos de $0,5 \%$ do total de resíduos do país (BRASIL, 2019).

O paradigma atual na gestão de resíduos sólidos é a gestão integrada visando o desenvolvimento de medidas quem sejam ambientalmente eficazes, socialmente aceitas e economicamente viáveis. Desta feita, alguns países têm desenvolvido sistema de tratamento dos resíduos sólidos a fim de minimizar o seu impacto no ambiente. A Figura 1, abaixo, apresenta como os países realizaram a disposição e tratamento de resíduos sólidos urbanos.

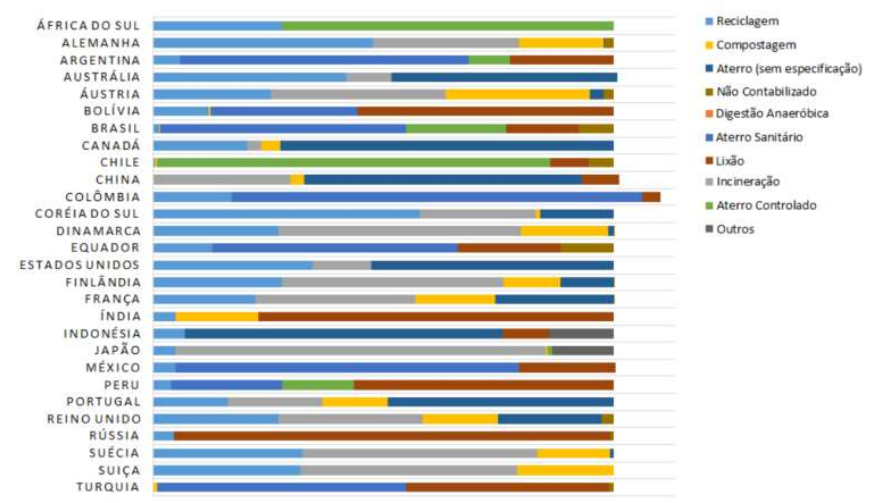

Figura 1: Disposição e tratamento de resíduos sólidos urbanos entre 2011-2017 em alguns países

Fonte: Antenor et al. (2020, adaptado de Kaza et al., 2018).

A Gestão Integrada de Resíduos Sólidos contribui para redução dos impactos ambientais negativos, otimização dos recursos financeiros aplicados e agrega ao gerenciamento de resíduos sólidos uma flexibilidade orientada pelas características da comunidade, o que permite melhoria continuada, tendo como premissa a não geração, redução, reutilização, reciclagem, tratamento e disposição final adequada dos rejeitos (MARSHALL et al., 2013; BUENO, 2019).

\section{Vermicompostagem como proposta de tratamento de resíduos orgânicos}

Ao se verificar a realidade dos resíduos sólidos no Brasil, percebe-se o potencial de aplicação de técnicas de tratamento dos RSU, devido à grande geração de resíduos orgânicos. No âmbito dos resíduos sólidos domiciliares, por exemplo, geralmente a parcela de lixo orgânico chega a representar mais da metade do total coletado no país, de acordo com a Associação Brasileira de Empresas de Limpeza Pública e Resíduos Especiais (ABRELPE, 2013). De acordo com o levantamento do ABRELPE cerca de $170 \mathrm{~kg}$ de matéria orgânica são descartadas por pessoa a cada ano no Brasil. A fração orgânica se mantém como a principal componente dos RSU, com 45,3\%, conforme destaca a Figura 2 (ABRELPE, 2020).

Algumas das alternativas para o tratamento dos RSU são a compostagem e a vermicompostagem. Essas técnicas são formas simples e bastante eficientes de reciclar matéria orgânica vegetal e animal, fundamentadas na reciclagem de nutrientes, da matéria orgânica que mantém os solos vivos e produtivos e há possibilidade de aplicação desses processos no campo e na cidade de maneira ampla e benéfica. Sendo assim, evidencia-se insistir e melhorar o conhecimento desses tratamentos, uma vez que são ecologicamente corretos, de baixo custo e os produtos gerados podem ser utilizados em diferentes áreas da agricultura (CORRÊA et al., 2015). 


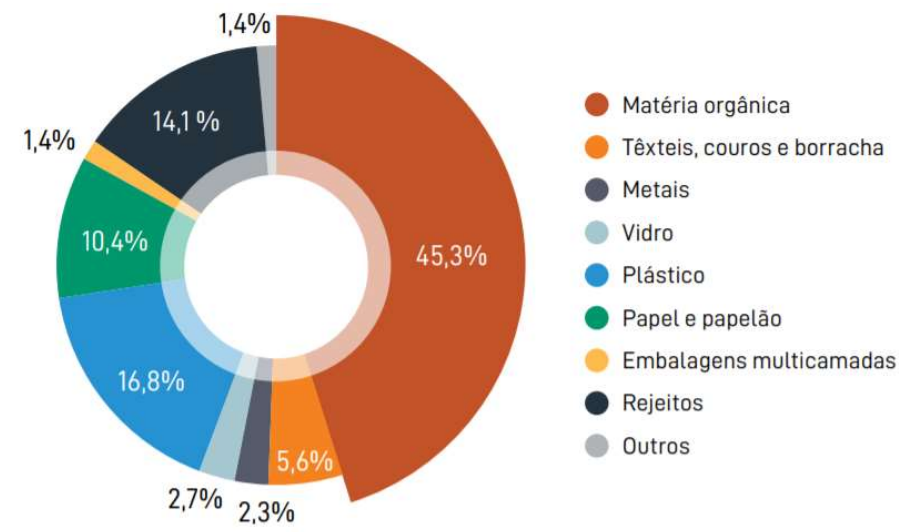

Figura 2: Gravimetria dos resíduos sólidos urbanos no Brasil. Fonte: ABRELPE (2020).

A Norma Brasileira (NBR) 13.591:1996 define a compostagem como o "processo de decomposição biológica da fração orgânica biodegradável dos resíduos, efetuado por uma população diversificada de organismos, em condições controladas de aerobiose e demais parâmetros [...]". E embora a compostagem seja uma prática antiga, a vermicompostagem foi desenvolvida mais recentemente e tem despertado muito interesse por ser uma tecnologia de baixo custo e facilmente adaptável à pequena produção (AQUINO, 2005).

Bidone et al. (1999) definem a vermicompostagem como um processo de compostagem no qual se utiliza minhocas para digestão da matéria orgânica e aumento da aeração e da drenagem do solo. Para Dal Bosco et al. (2017) esse é um processo controlado que utiliza a ação conjunta de minhocas e microrganismos, sob condição aeróbica, com a finalidade de estabilizar a matéria orgânica, inviabilizando o grau poluente e contaminante dos resíduos. Neste método, a maior parte dos compostos orgânicos é degradada e os resíduos são transformados em compostos ricos em nitrogênio, fósforo, potássio e substâncias húmicas (SONG et al., 2014).

Enquanto os microrganismos são responsáveis pela degradação bioquímica da matéria orgânica, as minhocas são as principais responsáveis pelo processo de fragmentação e condicionamento do substrato, executando uma função mais mecânica do que bioquímica. As minhocas agem como "liquidificadores mecânicos" triturando a matéria orgânica, modificando as características físicas, químicas e biológicas, após a ingestão do material elas excretem os coprólitos, que são produtos da biotransformação realizada pelos microrganismos naturalmente existentes nos intestinos das minhocas (DAL BOSCO et al., 2017; BIDONE; POVINELLI, 1999).

Dal Bosco et al. (2017) aponta que a técnica de vermicompostagem pode ser dividida em três principais etapas, sendo elas: Etapa inicial ou de degradação: Nesta etapa os microrganismos realizam o "ataque" inicial dos resíduos, ocorrendo os primeiros processos de mineralização; Etapa de colonização dos resíduos por parte das minhocas: Nesta etapa as moléculas orgânicas são transformadas em constituintes mais simples, por meio da ação dos microrganismos e processo de digestão das minhocas. Todos os compostos orgânicos são colonizáveis pelas minhocas, em menor ou maior grau, e a dificuldade de colonização advém das características de cada resíduo; Etapa de maturação: Nesta etapa ocorre a mineralização e humificação dos compostos. Tal processo origina substâncias de elevada estabilidade. 
As características do processo são semelhantes à compostagem tradicional, porém alguns parâmetros do ambiente da composteira devem ser adaptados às condições de sobrevivência das minhocas (QUINTELA, 2014). Da mesma forma que a compostagem, as condições ótimas para a vermicompostagem são estabelecidas considerando-se a temperatura, a umidade e a aeração (AQUINO, 2005).

\section{Fatores que influenciam na vermicompostagem}

A eficiência do processo de vermicompostagem depende das condições ambientais existentes. Para preparar os substratos antes de colocar as minhocas, independentemente se misturados ou não a outros resíduos, deve-se ter o cuidado para que a temperatura já esteja controlada. Caso contrário, as minhocas podem morrer, devido à alta temperatura e à liberação de amônia, no caso dos estercos (AQUINO, 2005).

$\mathrm{O}$ ambiente deve ser mantido a uma temperatura entre 20 e $25{ }^{\circ} \mathrm{C}$, umidade entre 70 e $85 \%$ e pH ligeiramente ácido, as minhocas apresentam maior sobrevivência em pH situados na faixa de 5,5 a 6,5, embora valores entre 6,5 e 7,5 sejam tolerados e aceitáveis (DAL BOSCO et al., 2017). Além disso, é importante que o meio não seja muito compactado e nem encharcado, para proporcionar a aeração necessária (QUINTELA, 2014). A umidade é primordial à sobrevivência das minhocas: tanto a escassez quanto o excesso de umidade podem ocasionar a rápida letalidade. Deste modo, os teores de umidade devem estar entre 75 e $90 \%$. Valores inferiores a $70 \%$ comprometem a respiração das minhocas, levandoas à morte por asfixia. Valores superiores a $90 \%$ também comprometem a sua sobrevivência, uma vez que o excesso de água preenche o espaço poroso, gerando zonas de anaerobiose, limitando o fornecimento de oxigênio (LOURENÇO, 2010).

Lourenço (2010) também destaca que o carbono e o nitrogênio do material são muito importantes para o processo de vermicompostagem. Para a boa aceitação das minhocas o material deve apresentar relação $\mathrm{C} / \mathrm{N}$ na faixa de 15/1 a 35/1. Valores inferiores a 15/1 indicam carência de carbono e excesso de nitrogênio, o que acelera o crescimento microbiano, elevando assim a temperatura e a liberação nitrogênio amoniacal ( $\mathrm{N}$-amoniacal), altamente tóxico às minhocas. Proporções de nitrogênio amoniacal superiores a $1 \mathrm{mg} . \mathrm{g}^{-1}$, são potencialmente tóxicas às minhocas.

\section{METODOLOGIA}

Todo o experimento foi realizado utilizando resíduo orgânico não cozido coletado no Restaurante Universitário da Universidade Federal do Tocantins, Campus Palmas. O processo de vermicompostagem foi conduzido entre março e julho de 2020. O experimento foi realizado tendo como base a pesquisa realizada por Lourenço e Coelho (2012), considerado o tempo de descanso de 7 dias. Essa adaptação a metodologia original proposta pelos autores foi necessária a fim de se adequar melhor a realidade de um restaurante universitário, assim é possível deixar uma unidade (caixa, tanque, contêiner...) de compostagem para cada dia da semana. O detalhamento das etapas executivas do experimento é apresentado no fluxograma da Figura 3, logo abaixo. 


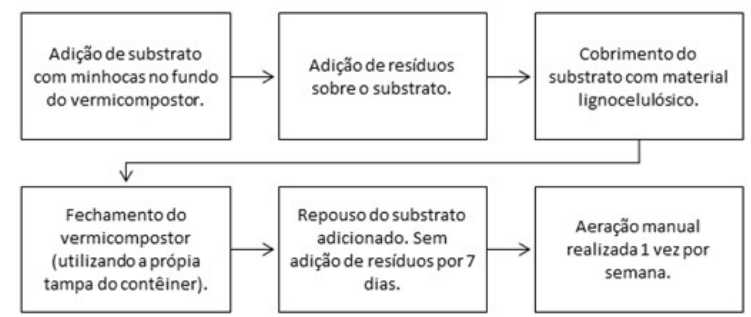

Figura 3: Fluxograma do detalhamento das etapas executivas do vermicompostor

A vermicompostagem se processou em um vermicompostor confeccionado a partir de caixas plásticas tipo contêiner. Foram utilizadas duas caixas com volume de 15 litros, conforme Figura 04, empilhadas uma na outra e cobertura apenas na caixa superior; foi inserida uma torneira de bebedouro e com o auxílio de uma furadeira com broca de 5 milímetros foram feitos furos na tampa e no fundo da caixa que fica empilhada em cima. O propósito desses furos foi de permitir o chorume escorrer para caixa que fica embaixo. Desta maneira, a caixa debaixo é responsável pela coleta do chorume, produto da decomposição da matéria orgânica.

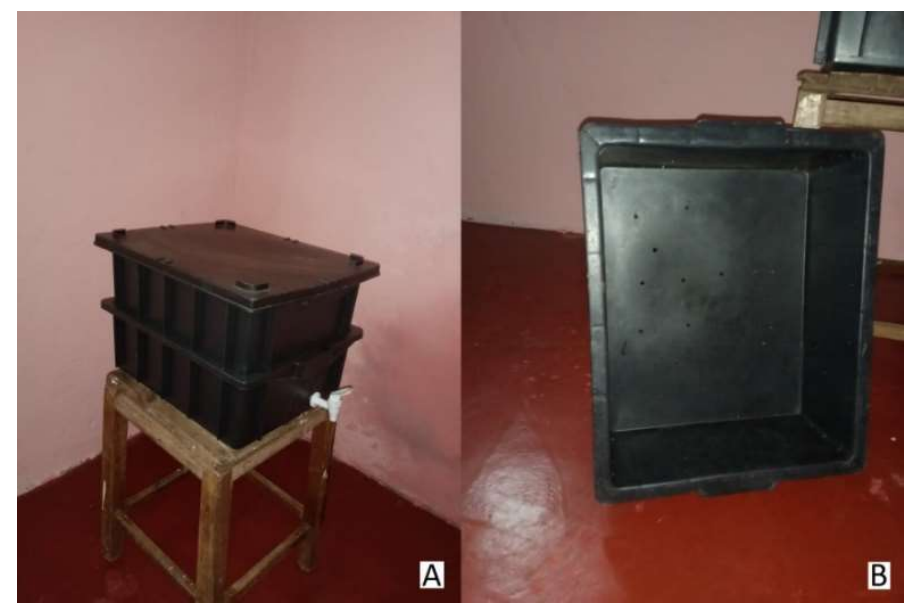

Figura 4: (A) Vermicompostor de caixas plásticas tipo contêiner; (B) Furos no fundo do vermicompostor

Os resíduos não cozidos foram coletados ao longo de três semanas, iniciadas em 21 de março de 20. Os principais resíduos coletados foram: cascas de banana, beterraba, cenoura, abóbora, maçã, chuchu, além de bora de café, casca de ovos; e folhas secas e serragem utilizadas como material lignocelulósico, esses últimos também coletados no campus da Universidade. Foram adicionados $2 \mathrm{~kg}$ de resíduo orgânico a proporção de 1 parte de matéria seca a cada semana, até encher o vermicompostor.

Neste estudo foram utilizadas 150 minhocas da espécie Eisenia foetida, popularmente conhecida como minhoca californiana ou minhoca vermelha. Após os 7 dias iniciais, foram adicionados resíduos outras 2 vezes, desta vez sobre os resíduos já decompostos. Nessas adições de substrato foram novamente adicionados material lignocelulósico.

A medição da temperatura seu deu com uso de um termômetro digital tipo espeto $\left(-45 /+230^{\circ} \mathrm{C}\right)$. $\mathrm{O}$ termômetro era introduzido à massa de resíduos, em três pontos distintos nas extremidades superior e inferior (5,0 cm da superfície) e centro. A análise dos parâmetros do solo foi realizada seguindo as diretrizes propostas no manual de métodos de análise de solo da Empresa Brasileira de Pesquisa Agropecuária (EMBRAPA) (DONAGEMA et al., 2011). 


\section{Análise do pH}

Para a aferição do $\mathrm{pH}$ inicialmente se procedeu a preparação da solução de $\mathrm{CaCl}_{2}$ (cloreto de cálcio). Na preparação da solução foram pipetadas $10 \mathrm{~mL}$ da solução padrão de $\mathrm{CaCl}_{2} 1$ mol.L-1 em um balão volumétrico de $1 \mathrm{~L}$ e completado o volume com água destilada ou deionizada. A recomendação é que a condutividade elétrica dessa solução deve ser de aproximadamente $2,3 \mathrm{mS} . \mathrm{cm}^{-1}$. Pesou-se $10 \mathrm{~g}$ de solo (terra fina seca ao ar - TFSA) e adicionou-se em copo plástico de $100 \mathrm{~mL}$. Em seguida foi adicionado $25 \mathrm{~mL}$ da solução salina $\left(\mathrm{CaCl}_{2}\right.$ 0,01 mol L-1 $)$. A amostra foi agitada com um bastão de vidro individual por cerca de 60s e depois deixado em repouso por 1 hora. Após o repouso, a amostra foi novamente ligeiramente agitada e então se procedeu a leitura do pH.

\section{Análises de Nutrientes}

Os nutrientes foram classificados em macro ( $\mathrm{Al}, \mathrm{Ca}$ e $\mathrm{Mg}$ ) e micronutrientes ( $\mathrm{k}, \mathrm{Fe}, \mathrm{Cu}, \mathrm{Mn}, \mathrm{Zn}$ ). Os macronutrientes foram analisados com adição de uma solução de $\mathrm{KCl}$ (cloreto de potássio) 1 mol. $\mathrm{L}^{-1}$. Foram pesados $10 \mathrm{~g}$ de solo (TFSA), e colocados em Erlenmeyer de $125 \mathrm{~mL}$ com $100 \mathrm{~mL}$ de solução de cloreto de potássio. A amostra foi agitada por 5 minutos em um agitador horizontal circular. Depois da agitação foi deixada em repouso durante uma noite.

Por sua vez, os micronutrientes foram analisados com o auxílio de uma solução extratora de

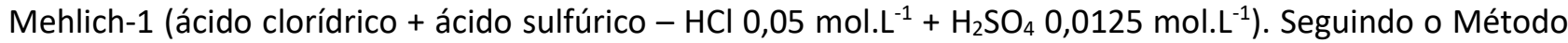
de Mehlich modificado, foram pesador $5 \mathrm{~g}$ de solo e colocados em Erlenmeyer de $50 \mathrm{~mL}$. Em seguida foram adicionados $25 \mathrm{~mL}$ da solução extratora de Mehlich-1. A amostra foi agitada por 5 minutos em agitador mecânico horizontal e filtrada imediatamente a suspensão. Por fim, com auxílio de um funil e papel filtro, as amostras líquidas foram filtradas, transferidas para um balão volumétrico de $250 \mathrm{~mL}$, e aferido o volume com água deionizada. As amostras foram transferidas para frascos de acondicionamento e levadas para leitura no aparelho Absorção Atômica Perkin Elmer.

\section{Análises de Carbono e Nitrogênio}

Para determinação do carbono e nitrogênio foram adotados os métodos analíticos oficiais para fertilizantes e corretivos propostos pelo Ministério da Agricultura, Pecuária e Abastecimento (BRASIL, 2017). O restante das amostras que foram secas e trituradas logo que chegaram ao laboratório foram novamente moídas. A análise do nitrogênio se deu pelo método volumétrico do dicromato de potássio. Este método baseia-se na oxidação do carbono orgânico contido na amostra, por via úmida, com dicromato de potássio em excesso e ácido sulfúrico concentrado, promovendo-se aquecimento externo. A determinação do nitrogênio seguiu o macrométodo da liga de Raney que se fundamenta na amonificação de todas as formas não amoniacais de nitrogênio, seguida da destilação alcalina da amônia, que é recebida em uma solução de ácido bórico. Por fim, a relação $\mathrm{C} / \mathrm{N}$ foi calculada pela divisão dos resultados em porcentagem em massa obtidos para o carbono orgânico e o nitrogênio, ambos referidos à amostra em base seca. 


\section{RESULTADOS E DISCUSSÃO}

No transcorrer dos primeiros dias de experimento a temperatura se manteve em torno de $34^{\circ} \mathrm{C} \mathrm{e}$ foi diminuindo no decorrer do tempo até se estabilizar nos $25,2^{\circ} \mathrm{C}$ nos últimos 28 dias do experimento. A fim de conferir possíveis variações foram realizadas vistorias diárias a composteira. A Figura 5 apresenta os registros das medições de temperatura do experimento.

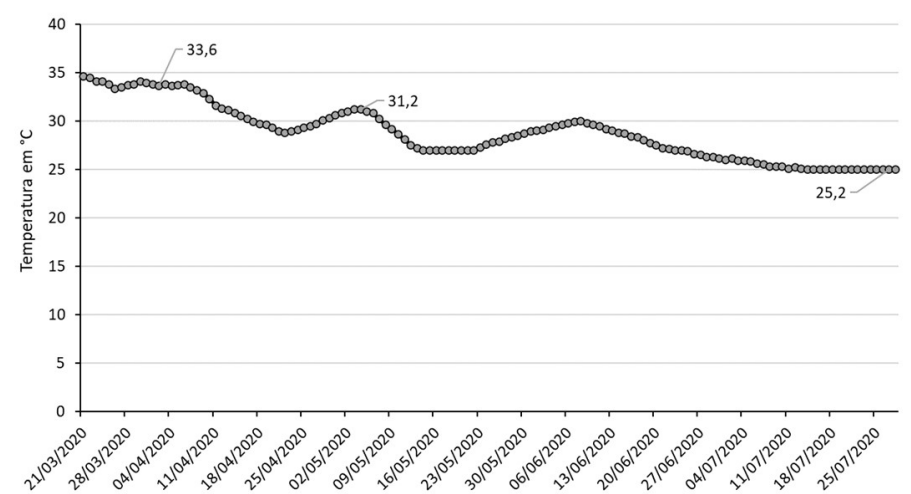

Figura 5: Registros da temperatura do substrato

Os primeiros sinais de geração de biofertilizante (chorume), na caixa debaixo, ocorreram no sétimo dia experimento. No decorrer do processo foram coletados cerca de 2,20 litros de biofertilizante. A partir do $45^{\circ}$ dia do experimento se o aparecimento de larvas de mosca, percebeu-se que as larvas entraram pela lateral do vermicompostor, por uma pequena brecha que ficou entre uma caixa e outra durante o empilhamento. As brechas foram corrigidas utilizando material geossintético. Nos primeiros testes de umidade (teste de umidade com a mão), conforme recomendação de Donagema et al. (2011), evidenciouse a necessidade de acrescentar matéria seca a fim de reduzir a umidade do substrato. Durante cinco dias foram realizadas inspeções para retirada de larvas e realizadas aerações manuais mais frequentes.

Nos 20 dias seguintes não foi mais identificada a presença de larvas de moscas e notou-se umidade normal. Houve nesse ínterim uma redução drástica na quantidade de minhocas, associada provavelmente pelos fatos acima mencionados. Desta maneira, foram acrescentadas 50 minhocas e 30 dias depois já se notou aumento reprodutivo das minhocas. As temperaturas em junho, no Tocantins, começam a aumentar significativamente. Esse aumento impactou o experimento. No início deste período, observou-se uma variação na temperatura, que já havia se estabilizado há um tempo, por conta do aumento as minhocas estavam saindo do composto e se alojando nas laterais e tampa do vermicompostor. A fim de solucionar esse problema a tampa plástica (furada) foi substituída por um tecido "não-tecido" (TNT), flexível e poroso, que permitiu uma maior ventilação resolvendo o problema.

Cerca de 130 dias após o início da deposição dos resíduos notou-se estabilidade contínua de $25^{\circ} \mathrm{C} \mathrm{e}$ mudança na coloração do substrato para o marrom escuro. Além disso, foi observada a presença de odor terroso. As evidências de maturação se deram 60 dias antes do recomendado por Lourenço et al. (2012), essa diferença pode estar associada as características dos resíduos depositados, e da adição posterior de minhocas que pode ter acelerado o processo.

As amostras foram então retiradas para análise físico-química. As amostras foram passadas por 
uma peneira de $10 \mathrm{~mm}$ para retirada de material grosseiro. A análise foi realizada mais de 1 mês depois, devido a algumas medidas de isolamento em razão da pandemia da Covid-19. A amostra foi armazenada adequadamente em saco plástico limpo sem uso, e analisada dentro do prazo permitido. Ao final do processo foram contadas 140 minhocas.

As amostras foram encaminhadas a dois laboratórios particulares de solos da cidade de Palmas. Os resultados das análises do $\mathrm{pH}$, análises dos nutrientes (Tabela 02), e da análise textural (03) são apresentados a seguir. $\mathrm{O}$ valor do $\mathrm{pH}$ foi de 6,95 , equivalente a um solo ligeiramente ácido e dentro da faixa a aceitável segundo Dal Bosco et al. (2017). Além disso, esse valor é próximo dos encontrados por Cotta et al. (2015) para um substrato de resíduos vegetais e serragem de madeira aos 98 dias (pH =6,74); e abaixo do $\mathrm{pH}$ encontrado por Quintela (2014) $(\mathrm{pH}=7,5)$.

Os valores dos nutrientes foram detectados e tiveram a sua análise comparada na Instrução Normativa $n^{\circ} 61$ de 8 de julho de 2020 (IN61) do Ministério da Agricultura, Pecuária e Abastecimento e que estabelece as regras sobre definições, exigências, especificações, garantias, tolerâncias, registro, embalagem e rotulagem dos fertilizantes orgânicos e dos biofertilizante, destinados à agricultura.

A amostra apresentou fósforo (P) extraído pelo método Mehlich com valor de $297,8 \mathrm{mg} \cdot \mathrm{dm}^{-3}$, a IN61 não estabelece limites ou percentuais mínimos para fósforo, assim a sua comparação foi estabelecida com o obtido em outros trabalhos. Os valores de fósforo encontrados por Sena et al. (2019), de Loureiro et al. (2007) que obtivam cerca de 0,9 g. $\mathrm{Kg}^{-1}$, e Suszek et al. (2007), obtiveram uma média de $2,74 \mathrm{~g} \mathrm{Kg}^{-1}$, os valores não foram convertidos para o sistema utilizado neste estudo. Os resultados podem estar associados ao número de dias do processo dos autores citados que foi inferior e a própria natureza do substrato. Todavia é evidente a necessidade de estudos posteriores mais pontuais para procurar estabelecer uma relação mais coesa entre a vermicompostagem e o teor de fósforo.

Tabela 2: Resultados da análise dos nutrientes

\begin{tabular}{|c|c|c|c|c|c|c|c|c|c|c|c|c|c|}
\hline $\begin{array}{c}P \\
\text { (meh) }\end{array}$ & $\mathrm{S}-\mathrm{SO}_{4}^{-2}$ & $\mathbf{K}^{+}$ & $\mathrm{Ca}^{2+}$ & $\mathrm{Mg}^{2+}$ & $\mathrm{Al}^{3+}$ & $\mathrm{H}+\mathrm{Al}$ & M.O. & c.o. & B & $\mathrm{Cu}$ & $\mathrm{Fe}$ & $\mathrm{Mn}$ & $\mathrm{Zn}$ \\
\hline \multicolumn{2}{|c|}{$\mathrm{mg} \cdot \mathrm{dm}^{-3}$} & \multicolumn{5}{|c|}{$\mathrm{cmol}_{\mathrm{c} \cdot \mathrm{dm}^{-3}}$} & \multicolumn{2}{|c|}{ g.dm ${ }^{-3}$} & \multicolumn{5}{|c|}{$\mathrm{mg} \cdot \mathrm{dm}^{-3}$} \\
\hline 297,8 & 186,37 & 5,78 & 4,54 & 3,8 & 0 & 3,1 & 256,25 & 148,64 & 2,03 & 0,4 & 53,54 & 40,54 & 8,07 \\
\hline
\end{tabular}

O valor obtido para o potássio $(\mathrm{k}), 5,78 \mathrm{cmol}_{\mathrm{c}} \cdot \mathrm{dm}^{-3}$ (cerca de 2,26 quando convertido para $\mathrm{g} . \mathrm{Kg}^{-1}$ ), está próximo do obtido por Loureiro et al. (2007), p =1,9 g. $\mathrm{Kg}^{-1}$, e em experimento de vermicompostagem com 27 dias; e de Loureiro e Aquino (2004) que encontraram 1,8 g. $\mathrm{Kg}^{-1}$ depois do segundo para potássio (27 dias). Para o cálcio a amostra apresentou $1,77 \mathrm{~g} \cdot \mathrm{Kg}^{-1}$ (valor convertido), bem abaixo dos valores obtidos por Loureiro et al. (2007), ca = 9,7 g.Kg-1 , Loureiro e Aquino (2004), ca = 9,4 g. $\mathrm{Kg}^{-1}$ e Nuernberg (2014), ca = 6,48 g. $\mathrm{Kg}^{-1}$. O teor de cálcio deste estudo (0,17\%) está abaixo do 1\% exigido pela IN61.

Quanto ao magnésio, o valor obtido foi de 1,49 g. $\mathrm{Kg}^{-1}$ (valor convertido), bastante próximo do obtido por Loureiro et al. (2004), 1,60 g. $\mathrm{Kg}^{-1}$ e por Loureiro et al. (2007), 1,7 g. $\mathrm{Kg}^{-1}$. O valor encontrado representa um percentual de $0,148 \%$, também abaixo do $1 \%$ exigido pela IN61. Os resultados para os micronutrientes $\mathrm{B}, \mathrm{Cu}, \mathrm{Fe}, \mathrm{Mn}$ e $\mathrm{Zn}$ estão todos dentro do mínimo exigido pela IN61. Por fim, no que diz respeito ao Nitrogênio e Carbono Orgânico, os resultados demonstram que o composto obtido no processo 
de vermicompostagem apresenta baixo teor de $\mathrm{N}$, e alto teor de C.

Tabela 3: Resultados da análise textural

\begin{tabular}{l|l|l|l|l|l|l}
\hline M.o. & C.o. & Areia & Argila & Silte & Nitrogênio & $\begin{array}{l}\text { Carbono } \\
\text { Orgânico }\end{array}$ \\
\hline $\mathbf{g . \mathbf { d m } ^ { - 3 }}$ & $\mathbf{g} \cdot \mathbf{K g}^{-1}$ \\
\hline 256,25 & 202 & 611 & 187 & 1,3 & 41,5 \\
\hline
\end{tabular}

A condição desses parâmetros sobre influência do tempo de maturação do substrato conforme aponta Nuernberg (2014); Guermandi (2015) destaca que no decorrer do processo de degradação da matéria orgânica há uma tendência de perda de C e aumento de N por unidade de material compostável, resultando em uma relação $\mathrm{C} / \mathrm{N}$ com menor valor. Os valores de Nitrogênio e Carbono Orgânico estão acima do percentual mínimo exigido, mas a relação C/N ficou em $32 \%$, acima dos $20 \%$ máximos determinados pela IN61.

\section{CONCLUSÃO}

Após os resultados obtidos foi possível concluir que apesar de constituir em uma técnica relativamente simples faz-se necessária a observação periódica e aferição de parâmetros como umidade e temperatura, do contrário o vermicompostor possibilita a fuga de minhocas e intrusão de insetos. A maturação do composto aconteceu 60 dias antes do recomendado por Lourenço et al. (2012), as diferenças adotadas no experimento, como a redução do número de dias de coleta, e as temperaturas mais quentes, típicas do Tocantins, podem ser algumas das possíveis origens da diferença.

Foi obtido um substrato com condições de $\mathrm{pH}$ e umidade adequados para o uso na agricultura, mas com condições nutricionais abaixo das exigências mínimas determinadas pela IN61 para alguns parâmetros, caso do vermicomposto seja destinado a agricultura..

\section{REFERÊNCIAS}

ABRELPE. Associação Brasileira de Empresas de Limpeza Pública e Resíduos Especiais. Panorama dos Resíduos Sólidos no Brasil, 2013.

ABRELPE. Associação Brasileira de Empresas de Limpeza Pública e Resíduos Especiais. Panorama dos Resíduos Sólidos no Brasil, 2020.

ANTENOR, S.; SZIGETHY, L.. Resíduos sólidos urbanos no Brasil: desafios tecnológicos, políticos e econômicos. IPEA Centro de Pesquisa em Ciência, Tecnologia e Sociedade, 2020.

ANTUNES, R. M.; CASTILHOS, R. M. V.; CASTILHOS, D. D.; LEAL, O. A.; DICK, D. P.; ANDREAZZA, R.. Transformações químicas dos ácidos húmicos durante o processo de vermicompostagem de resíduos orgânicos. Engenharia Sanitário e Ambiental, v.20, n.4, p.699-708, 2015. DOI: https://doi.org/10.1590/S1413-41522015020040114466

AQUINO, A. M.. Aspectos Práticos da Vermicompostagem. In: AQUINO, A. M.; ASSIS, R. L.. Agroecologia: princípios e técnicas para uma agricultura orgânica sustentável. Brasília,: Embrapa Informação Tecnológica, p.423-434, 2005.

BIDONE, F. R. A.; POVINELLI, J.. Conceitos básicos de resíduos sólidos. São Carlos: Universidade de São Paulo, 1999.

BRASIL. Ministério da Agricultura, Pecuária e Abastecimento. Secretaria de Defesa Agropecuária. Instrução Normativa № 61. Estabelece as regras sobre definições, exigências, especificações, garantias, tolerâncias, registro, embalagem e rotulagem dos fertilizantes orgânicos e dos biofertilizantes, destinados à agricultura. Brasília: DOU, 2020.

BRASIL. Secretaria Nacional de Saneamento - SNS. Sistema Nacional de Informações sobre Saneamento: Diagnóstico do Manejo de Resíduos Sólidos Urbanos - 2019. Brasília: SNS/MDR, 2020.

BRASIL. Ministério da Agricultura, Pecuária e Abastecimento. Fertilizantes e Corretivos: métodos analíticos oficiais para fertilizantes e corretivos. Brasília, 2017. 
BUENO, I. L. M.. Aplicação do Indicador da Qualidade das Condições para se Viver (IQCV) e do Indicador da Qualidade de Vida (IQV) para análise da Gestão de Resíduos Sólidos Urbanos no município de Jandaia/GO. Dissertação (Mestrado em Engenharia Ambiental) - Universidade Federal do Tocantins, Palmas, 2019.

CORRÊA, C. T.; SANTOS, J. S.. Vermicompostagem no tratamento de resíduos orgânicos domésticos. In: SEMANA DE EXTENSÃO, PESQUISA E PÓS-GRADUAÇÃO - CENTRO UNIVERSITÁRIO RITTER DOS REIS, 11. Anais, Porto Alegre 2015.

COTTA, J. A. O.; CARVALHO, N. L. C.; BRUM, T. S.; REZENDE, M. O. O.. Compostagem versus vermicompostagem: comparação das técnicas utilizando resíduos vegetais, esterco bovino e serragem. Engenharia Sanitária e Ambiental, v.20, n.1, p.65-78, 2015. DOI: https://doi.org/10.1590/S1413-41522015020000111864

DAL BOSCO, T. C.; GONÇALVES, F.; ANDRADE, F.C.; TAIATELE JUNIOR, I.; SILVA, J. S.; SBIZZARO, M.. Contextualização teórica: compostagem e vermicompostagem. In: DAL BOSCO, T. C.. Compostagem e vermicompostagem de resíduos sólidos: resultados de pesquisas acadêmicas. São Paulo: Blucher, 2017, p.19-43.

DONAGEMA, G. K.; CAMPOS, D. V. B.; CALDERANO, S. B.; TEIXEIRA, W. G.; VIANA, J. H. M.. Manual de métodos de análise de solo. 2. ed. Rio de Janeiro: Embrapa Solos, 2011.

GUERMANDI, J. I.. Avaliação dos parâmetros físicos, químicos e microbiológicos dos fertilizantes orgânicos produzidos pelas técnicas de compostagem e vermicompostagem da fração orgânica dos resíduos sólidos urbanos coletada em estabelecimentos alimentícios de São Carlos/SP. Dissertação (Mestrado em Hidráulica e Saneamento) - Universidade de São Paulo, São Carlos, 2015.

KAZA, S.; YAO, L. C.; BHADA-TATA, P.; VAN WOERDEN, F.. What a Waste 2.0: a global snapshot of solid waste management to 2050. Washington: World Bank, 2018.

LOUREIRO, D. C.; AQUINO, A. M.. Fauna epígea e atributos químicos durante compostagem e vermicompostagem de resíduos domiciliares. In: JORNADA DE INICIAÇÃO CIENTÍFICA DA UNIVERSIDADE FEDERAL RURAL DO RIO DE JANEIRO, 14.. Anais. Universidade Federal Rural do Rio de Janeiro, Rio de Janeiro, 2004.

LOUREIRO, D.; AQUINO, A. M.; ZONTA, E.; LIMA, E.. Compostagem e vermicompostagem de resíduos domiciliares com esterco bovino para a produção de insumo orgânico. Pesquisa Agropecuária Brasileira, v.42, n.7, p. 1043-4048, 2007. DOI: https://doi.org/10.1590/S0100$\underline{204 \times 2007000700018}$

LOURENÇO, N. M. G.. Vermicompostagem: gestão de resíduos orgânicos. Lisboa: Vírgula, 2010.

LOURENÇO, N. M.G.; COELHO, S. I. D.. Vermicompostagem nas escolas: manual prático para o professor. Lisboa: Sítio do Livro, 2012.

MARSHALL, R. E.; FARAHBAKHSH, K.. Systems approaches to integrated solid waste management in developing countries. Waste Management, v.33, p.988-1003, 2013. DOI: https://doi.org/10.1016/j.wasman.2012.12.023

NUERNBERG, A. C.. Vermicompostagem: estudo de caso utilizando resíduo orgânico do restaurante universitário da UTFPR Câmpus Curitiba - sede Ecoville. Monografia (Graduação em Tecnologia e processos ambientais) Universidade Tecnológica Federal do Paraná, Curitiba, 2015.

\section{QUINTELA, L. S.. Avaliação do processo de} vermicompostagem doméstica para tratamento da parcela orgânica dos resíduos sólidos domiciliares. Monografia (Graduação em Engenharia Ambiental) - Universidade Federal do Rio Grande do Sul, Porto Alegre, 2014.

SANTOS, A. S.. Avaliação da sustentabilidade na gestão de resíduos sólidos urbanos: estudo de caso envolvendo segmentos sociais do município de Feira de Santana, Bahia. Dissertação (Mestrado em Ciências ambientais) Universidade Estadual de Feira de Santana, Feira de Santana, 2015.

SENA, L. M.; ARRUDA, J. F.; COSTA, F. R. S.; ALMEIDA, F. B. B.; BRITO, P. O. B.; GONDIM, F. A. Revista Verde, v.14, n.2, p. 266-272, 2019. DOI: https://doi.org/10.18378/rvads.v14i2.6136

SONG, X.; LIU, M.; WU, D.; QI, L.; YE, C.; JIAO, J.; HU, F.. Heavy metal and nutrient changes during vermicomposting animal manure spiked with mushroom residues. Waste Management, v.34, n.11, p.1977-1983, 2014. DOI: https://doi.org/10.1016/j.wasman.2014.07.013

SUSZEK, M.; SAMPAIO, S. C.; MALLMANN, L. S.; SILVESTRO, M. G.. Aspectos físicos e químicos de vermicompostos produzidos a partir de esterco bovino e compostos de resíduos verdes urbanos. Engenharia na Agricultura, v.15, n.1, p.39-44, 2007.

A CBPC - Companhia Brasileira de Produção Científica (CNPJ: 11.221.422/0001-03) detém os direitos materiais desta publicação. Os direitos referem-se à publicação do trabalho em qualquer parte do mundo, incluindo os direitos às renovações, expansões e disseminações da contribuição, bem como outros direitos subsidiários. Todos os trabalhos publicados eletronicamente poderão posteriormente ser publicados em coletâneas impressas sob coordenação da Sustenere Publishing, da Companhia Brasileira de Produção Científica e seus parceiros autorizados. Os (as) autores (as)

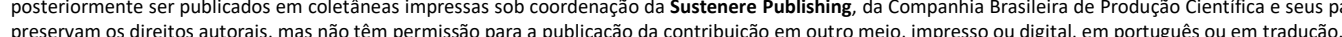

